\title{
TRANSDUCTIONAL ANALYSIS OF METHIONINE GENES IN PROTEUS MIRABILIS
}

\author{
W. O. K. GRABOW* \\ Department of Microbiology, University of Pretoria, Republic of South Africo \\ Received 10.v.71
}

\section{INTRODUCTION}

SIx structural genes (Smith, 1961; Smith and Childs, 1966; Childs and Smith, 1969) and two regulatory genes (Ayling and Chater, 1968; Lawrence, Smith and Rowbury, 1968; Chater and Rowbury, 1970) of the methionine pathway have been mapped in Salmonella typhimurium (see figs. 1 and 2). The requirement for methionine of another group of $S$. typhimurium mutants is due to an altered methionyl-sRNA synthetase (Gross and Rowbury, 1971). Loci homologous to some of the $S$. typhimurium genes have been identified in Escherichia coli and they map at corresponding locations (see Taylor, 1970). Apart from the met $A, H$, and met $\mathcal{F}, B, F$ clusters the members of which are not involved in consecutive biosynthetic steps, the methionine genes of S. typhimurium are scattered over the genome (Smith, 1961; Ayling and Chater, 1968). Four methionine structural genes of Pseudomonas aeruginosa (Calhoun and Feary, 1969) are also not arranged in an operon (Jacob and Monod, 1961). In contrast three methionine structural genes of Staphylococcus aureus are linked together in an " assembly line" (Harmon et al., 1966).

Cooper (1966) identified an $E$. coli gene which is involved in the conversion of D-methionine to the L-isomer. Methionine auxotrophs with a mutation in this gene do not respond to D-methionine whereas the wild-type grows equally well with D- or L-methionine (Lampen, Jones and Perkins, 1947; Huang, 1963) under aerobic conditions (Cooper, 1966). In interrupted mating experiments this gene was located near the lac region (Cooper, 1966) far from other methionine genes (see Taylor, 1970).

In Proteus mirabilis strain 13 the methionine pathway is similar to that in $S$. typhimurium and $E$. coli (Grabow and Smit, 1967) but the location of the genes was unknown. $P$. mirabilis is different in that it may synthesise methionine via S-methylcysteine (SMC-Grabow and Smit, 1967). This paper concerns the isolation and characterisation of $P$. mirabilis methionine structural and regulatory genes and a gene involved in the conversion of D- to L-methionine. Linkage studies by transduction provide information which relates to the regulation of methionine synthesis (Lawrence et al., 1968; Childs and Smith, 1969), the relevance of SMG, and is of taxonomic interest (Coetzee, Smit and Prozesky, 1966; Jones and Sneath, 1970). To permit comparisons between linkage maps the nomenclature is the same as that used for corresponding $S$. typhimurium and $E$. coli genes (see Sanderson, 1970; Taylor, 1970).

* Present address: National Institute for Water Research of the South African Council for Scientific and Industrial Research, P.O. Box 395, Pretoria, Republic of South Africa. 


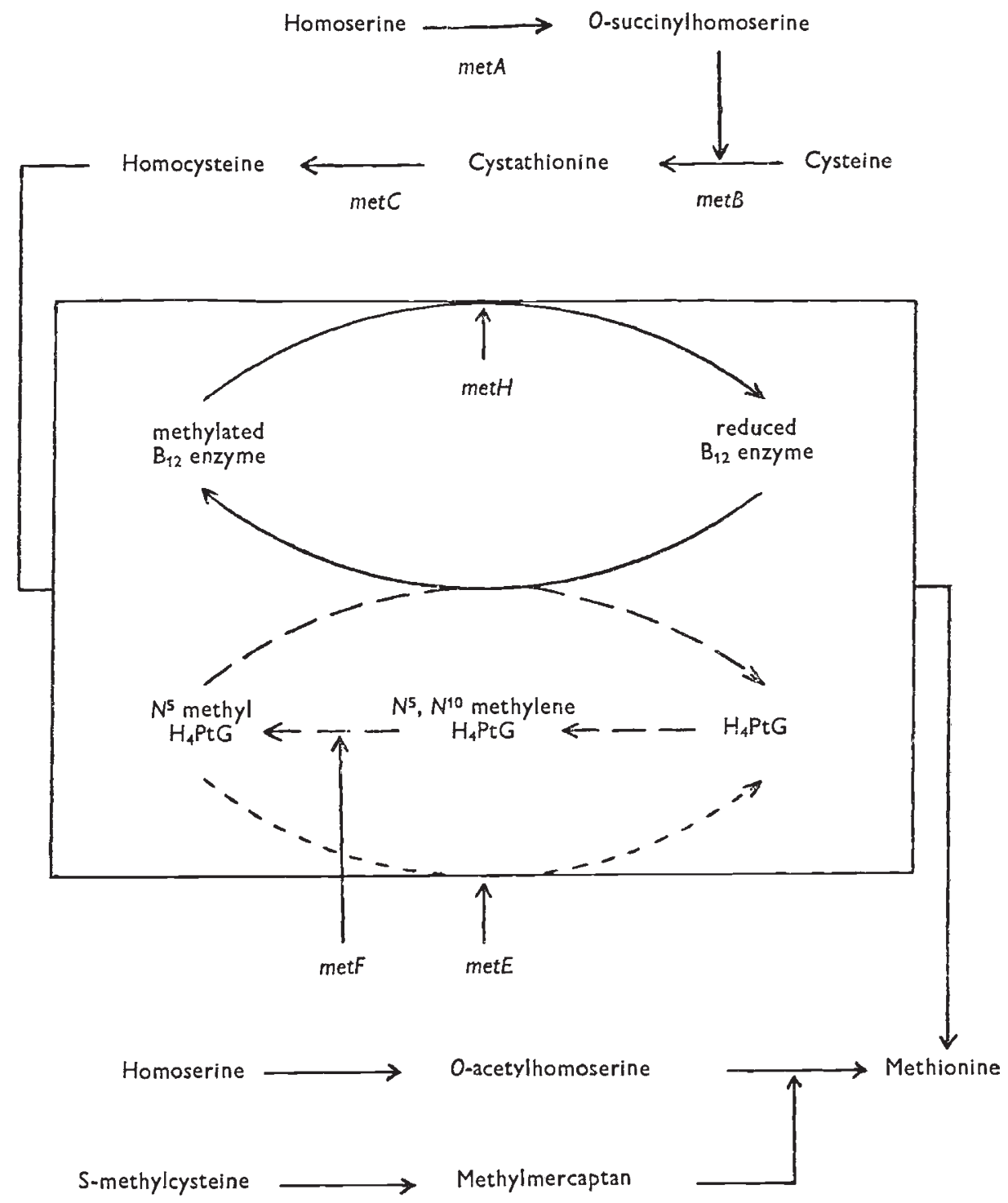

FIG. 1. - The pathway of methionine synthesis in Salmonella typhimurium (after Smith and Childs, 1966; Childs and Smith, 1969) and in Neurospora via S-methylcysteine (after Moore and Thompson, 1967). Short broken line arrow = tetrahydropteroyltriglutamate only; long broken line arrow = either tetrahydropteroyltri- or monoglutamate; $m e t A=$ homoserine $O$-transsuccinylase; $m e t B=$ cystathionine synthetase; $m e t C=$ cystathionase; $m e t E=\mathcal{N}^{5}$-methyltetrahydropteroyl-triglutamate-homocysteine transmethylase; met $F=\mathcal{N}^{5}, \mathcal{N}^{10}$-methylene tetrahydrofolate reductase; metH $=$ cobalamin-dependent $\mathcal{N}^{5}$-methyltetrahydrofolate-homocysteine transmethylase.

\section{Media and chemicals}

\section{Materials AND Methods}

The minimal medium (MM) agar was that of Grabow and Smit (1967) and the broth that of Coetzee and Sacks $(1960 a)$. D- and L- isomers of 
methionine and DL-ethionine were obtained from Dr Theodor Schuchardt, München, Germany; vitamin $B_{12}$ and DL-norleucine from British Drug Houses, Poole, England; DL-cystathionine from Sigma Chemical Company, St Louis, U.S.A.; $\mathcal{N}$-methyl- $\mathcal{N}^{\prime}$-nitro- $\mathcal{N}$-nitrosoguanidine (NG) from Aldrich Chemical Co., Milwaukee, U.S.A., and S-methyl-L-cysteine (SMC) from Calbiochem, California, U.S.A. All other growth factors were supplied by Nutritional Biochemicals Corporation, Gleveland, U.S.A., and $O$-succinylDL-homoserine was prepared by the method of Flavin and Slaughter (1965).

\section{Bacteria}

Mutants were derived from wild-type Proteus mirabilis strain 13 or its streptomycin-resistant mutant str-rl (13 str-r of Coetzee and Sacks, 1960b). Auxotrophs were obtained after induction with ultraviolet light, manganese chloride or hydrogen peroxide (Grabow and Smit, 1967) or NG using the methods of Adelberg, Mandel and Chein Ching Chen (1965) or Childs and Smith (1969). Mutants were characterised auxanographically (Grabow and Smit, 1967). Strain metE3 (table 1) was used to isolate mutants of the metEmetH genotype as described by Childs and Smith (1969) and metE3 mutants with leaky secondary mutations were discarded as they could have been metE3metG mutants (Smith and Childs, 1966). Eight phenotypically different arginine auxotrophs of $P$. mirabilis strain 13 were kindly provided by Professor O. W. Prozesky (Prozesky, 1967, 1968).

Using the methods of Lawrence et al. (1968) mutants resistant to inhibition by the methionine analogues ethionine and norleucine $(1 \mathrm{mg} . / \mathrm{ml}$.) were isolated and their excretion of methionine tested by syntrophism tests at $25^{\circ} \mathrm{C}$. or $37^{\circ} \mathrm{C}$. in which the mutants were streaked parallel to met $A$ or $\operatorname{met} F$ auxotrophs on $\mathrm{MM}$ agar. Attempts to isolate methionine auxotrophs deficient in D-methionine utilisation were in accordance with Cooper (1966) except that NG was used for mutagenesis instead of ultraviolet light. Double auxotrophs were isolated as described by Prozesky and Coetzee (1966) and Prozesky (1967), and auxotrophs resistant to inhibition by methionine analogues according to Ayling and Chater (1968). The final group of mutants used consisted of one mutant of each phenotype retained from each isolation experiment. All strains were kept on agar slopes at $4^{\circ} \mathrm{C}$. and subcultured once every 6 months. Each subculture was routinely tested for reversions. Unless otherwise stated, incubation was at $37^{\circ} \mathrm{C}$.

\section{Transduction}

Phage preparation and assay techniques were those of Adams (1959). Lysates of the transducing phage 34.13 (Coetzee and Sacks, 1960a) containing $5 \times 10^{9}-2 \times 10^{10}$ plaque-forming units $/ \mathrm{ml}$. were prepared by an agarlayer technique (Prozesky, de Klerk and Coetzee, 1965). Final lysates contained less than 50 plaque-forming units/ml. 13vir (Prozesky, 1968; Coetzee and Smit, 1970). The transduction procedure of Prozesky and Coetzee (1966) and Prozesky (1968) was used. Controls to detect bacteria in phage preparations and those in which recipients were treated with lysates prepared on homologous and wild-type bacteria respectively were included. All plates were incubated for 48 hours.

Wild-type transductants were selected on MM agar and auxotrophic donor phenotype transductants on $\mathrm{MM}$ agar $+50 \mu \mathrm{g} . / \mathrm{ml}$. of the required growth factor (Smith and Childs, 1966). MetE mutants were grown on 
MM agar $+0 \cdot 1 \mu \mathrm{g} . / \mathrm{ml}$. vitamin $\mathrm{B}_{12}$ (Smith, 1961). Wild and donor-type transductants were distinguished after replication to MM agar and incubation for 24 hours (Lederberg and Lederberg, 1952). The methods of Ayling and Chater (1968) were used to select for resistance to inhibition by methionine analogues and the selection of markers linked to met $H$ was as described by Childs and Smith (1969).

\section{Genetical mapping}

Linkage was tested by the frequency of co-transduction in two-point crosses, donor-phenotype transduction and the transduction of double mutants with phage prepared on the wild-type (Smith, 1961; Ayling and Chater, 1968; Prozesky, 1968; Childs and Smith, 1969).

\section{(i) Auxotrophs}

\section{REsults}

The growth responses of 55 single-site auxotrophs (table 1) to intermediates in the methionine pathway indicate that they represent mutations at three different gene loci similar to those of the met $A, E$ and $F$ mutants of Salmonella typhimurium (Smith and Childs, 1966) and so they were designated accordingly. Auxotrophs similar to met $B, C$ and $G$ mutants of $S$. typhimurium (Smith and Childs, 1966) were not encountered. On the basis of previous

\section{TABLE 1}

Growth responses of methionine auxotrophs of Proteus mirabilis to methionine intermediates

Intermediate

Cysteine

Homoserine

$O$-succinylhomoserine

Cystathionine

Homocysteine

Vitamin $B_{12}$

S-methylcysteine

Methionine

Number of mutants in each group

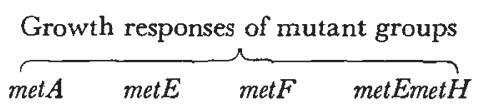

$\begin{array}{llll}- & - & - & - \\ + & - & - & - \\ + & - & - & - \\ + & - & - & - \\ - & + & - & - \\ - & + & + & + \\ + & + & + & + \\ 16 & 28 & 11 & 21\end{array}$

studies of the metabolic defects of some of these mutants (Grabow and Smit, 1967) the ability of met $E$ and $F$, and the inability of met $A$ auxotrophs to utilise SMC is shared with similar auxotrophs of Neurospora crassa (Wiebers and Garner, 1964; Moore and Thompson, 1967) but differs from those of Escherichia coli (Grabow and Smit, 1967) and Pseudomonas aeruginosa (Calhoun and Feary, 1969).

Treatment of metE3 cultures with NG yielded mutants (table 1) which retained the ability to grow with methionine but no longer respond to vitamin $\mathrm{B}_{12}$. These auxotrophs probably possess the same defects as metEmetH mutants of $S$. typhimurium (Childs and Smith, 1969) for which genetical evidence will be given later.

The phenotypes of the metE and metEmet $H$ mutants indicate that the two routes for the methylation of homocysteine catalysed by the $\mathcal{N}^{5}$-methyl- 
tetrahydropteroyltriglutamate-homocysteine transmethylase (metE) and cobalamin-dependent $\mathcal{N}^{5}$-methyltetrahydrofolate-homocysteine transmethylase (met $H$ ) enzymes described for $S$. typhimurium (Woods, Foster and Guest, 1965; Childs and Smith, 1969) also occur in P. mirabilis and that like S. typhimurium (Gauthen, Foster and Woods, 1966) and E. coli (Galivan and Huennekens, 1970) the intracellular concentration of vitamin $B_{12}$ is low in $P$. mirabilis so that the met $H$ route only functions when vitamin $\mathrm{B}_{12}$ is supplied. As homocysteine is normally methylated via the met $E$ route, met $H$ mutants are phenotypically wild and $m e t H$ mutations can only be identified in metE auxotrophs (see Childs and Smith, 1969).

\section{(ii) Mutants resistant to inhibition by methionine analogues}

Two groups of resistant mutants were isolated, one resistant to ethionine and the other resistant to both ethionine and norleucine. Eight members of the latter group were isolated on $\mathrm{MM}$ agar + norleucine, and the remaining three members of that group and the five members of the former group on MM agar + ethionine. Colony growth of all the mutants on MM agar was slow as compared with wild-type. The similarity to the met $f$ and $K$ regulatory mutants of $S$. typhimurium (Lawrence et al., 1968) justified use of the same designation. The $P$. mirabilis mutants differed from the $S$. typhimurium mutants in that they appeared not to overproduce methionine at either $37^{\circ} \mathrm{C}$. or $25^{\circ} \mathrm{C}$. As no $\alpha$-DL-methylmethionine was available it was not possible to isolate mutants like the metI mutants of $S$. typhimurium (Lawrence et al., 1968).

\section{(iii) Methionine auxotrophs unable to utilise $D$-methionine}

All methionine auxotrophs of $P$. mirabilis grew equally well on MM agar + either D- or L-methionine, similar to the situation in $E$. coli (Cooper, 1966). Cultures of $m e t F 1, F 5, E 4, E 5, A 2$, and $A 3$ were treated with NG and about $1 \times 10^{5}$ clones of each were screened by replica plating for inability to grow on D-methionine. No such mutants were encountered which is surprising since Cooper isolated many of them from $E$. coli.

\section{(iv) Transductional analysis of met mutants}

Reciprocal two-point crosses in all combinations between met $A, E$ and $F$ mutants yielded less than 12 wild-type transductants in crosses between mutants of the same phenotype whereas more than 1000 were obtained in crosses with different phenotypes (table 2). The numbers of prototrophs in the latter crosses were comparable to those in crosses with the wild-type donor. These results indicate that the met $A, E$ and $F$ auxotrophs represent three genes which are not co-transducible (see Smith, 1961). In crosses with met $A$ recipients the yield of wild-type recombinants was always more than 4000 which is about twice as high as that with metE or $F$ recipients (table 2). The donor capacity of metA mutants did not differ from that of the latter two groups. MetE855 and metE933 had poor recipient and donor capacities and are possibly multisite mutants (Demerec and Ozeki, 1959; Hartman, Loper and Šrman, 1960). MetE572 and metE291 were poor recipients but were normal as donors; they may be deficient in recombination and replication of deoxyribonucleic acid (Alberts and Frey, 1970). The results of crosses between metEmet $H$ mutants plated on $\mathrm{MM}$ agar + vitamin $\mathrm{B}_{12}$ followed by replication to $\mathrm{MM}$ agar to detect metEmet $H^{+}$recombinants, indicated (table 3 ) that all 
metH mutations are located close together, perhaps in one gene (Childs and Smith, 1969).

The methionine mutants behaved like point mutations since they yielded revertants at some stage of the investigation and they could participate as donors or recipients in transduction experiments. None of the mutants had the characteristics of deletion mutations (Hartman et al., 1960; Itikawa and Demerec, 1967). No mixed colonies were encountered among transductant clones.

\section{TABLE 2}

The frequency of transduction between met auxotrophs

\begin{tabular}{lrrrrrrr} 
& \multicolumn{7}{c}{ Donor } \\
Recipient & metA1 & metA2 & metE1 & metE3 & metF1 & metF2 & wild-type \\
metA1 & 0 & 11 & 4840 & 4620 & 4740 & 4980 & 4740 \\
metA2 & 1 & 2 & 4730 & 4540 & 4600 & 4890 & 4640 \\
metA1303 & 3 & 8 & 5342 & 5110 & 5280 & 5340 & 5230 \\
metE1 & 1620 & 1634 & 0 & 3 & 1584 & 1542 & 1602 \\
metE3 & 1586 & 1620 & 2 & 1 & 1434 & 1590 & 1597 \\
metE687 & 1573 & 1640 & 6 & 4 & 1740 & 1620 & 1638 \\
metF1 & 2342 & 2394 & 2180 & 2420 & 0 & 7 & 2383 \\
metF2 & 2367 & 2247 & 2347 & 2407 & 6 & 0 & 2336 \\
metF1445 & 2212 & 2200 & 2208 & 2286 & 8 & 3 & 2217
\end{tabular}

Wild-type recombinants were selected and colony numbers on control plates subtracted.

TABLE 3

The frequency of transduction between metE 3 met $\mathrm{H}$ mutants

$\begin{array}{lcccccc}\text { Recipient } & \begin{array}{l}\text { metE3 } \\ \text { metH1 }\end{array} & \begin{array}{l}\text { metE3 } \\ \text { metH3 }\end{array} & \begin{array}{l}\text { metE3 } \\ \text { metH10 }\end{array} & \begin{array}{l}\text { metE3 } \\ \text { metH12 }\end{array} & \begin{array}{l}\text { metE3 } \\ \text { metH20 }\end{array} & \text { wild-type } \\ \text { metE3metH1 } & 0 & 0 & 4 & 3 & 9 & 986 \\ \text { metE3metH3 } & 3 & 1 & 4 & 8 & 4 & 932 \\ \text { metE3metH10 } & 6 & 2 & 0 & 10 & 2 & 1021 \\ \text { metE3metH12 } & 8 & 0 & 7 & 0 & 5 & 922 \\ \text { metE3metH20 } & 2 & 1 & 6 & 11 & 0 & 956\end{array}$

Selection was for metEmet $H^{+}$recombinants.

Donor-phenotype transduction was detected only between met $A$ and $H$ mutants. Typical results of crosses in which metE3metH mutants were transduced with metA donors appear in table 4 . The counts of metEmet $H^{+}$recombinants in table 4 were obtained by dividing the number of colonies on $M M$ agar + vitamin $B_{12}$ by two since a preliminary test indicated that the ratio of the relative numbers of metE+ $E^{+} t H$ and metEmet $H^{+}$recombinants in the latter crosses did not differ significantly from $1: 1$ (see Lawrence et al., 1968; Childs and Smith, 1969). Reciprocal crosses were not possible since $m e t A$ represents a block proximal to $m e t H$ in methionine synthesis (see fig. 1) and selection of donor-phenotype transductants is not possible. Organisms with the three mutations metE, $H$ and $A$ could have been selected and used to prove linkage between $m e t A$ and $H$ by transduction with the wild-type donor 
but this was not attempted. It is also not possible to construct these mutants by transduction (Glansdorff, 1965) since phage $34 \cdot 13$ causes lysogenic conversion (Coetzee, 1961) which results in non-adsorption of homologous phage (see Prozesky, 1968).

TABLE 4

Donor-phenotype transduction in crosses between metEmetH and metA mutants

\begin{tabular}{|c|c|c|}
\hline Cross & \multirow[b]{2}{*}{$\begin{array}{l}\text { Transductants* } \\
\text { Prototrophs/total }\end{array}$} & \multirow{2}{*}{$\begin{array}{c}\text { Percentage } \\
\text { linkage }\end{array}$} \\
\hline Recipient & & \\
\hline metE $3 m e t H 1 \times \operatorname{met} A 1$ & $338 / 514$ & $34 \cdot 2$ \\
\hline metE 3 metH $3 \times$ metA2 & $462 / 682$ & $32 \cdot 3$ \\
\hline metE 3 metH8 $\times$ metA 3 & $424 / 649$ & $34 \cdot 7$ \\
\hline met $E 3 m e t H 12 \times$ metA 4 & $521 / 785$ & $33 \cdot 6$ \\
\hline metE 3 met $H 19 \times \operatorname{met} A 5$ & $473 / 708$ & $33 \cdot 2$ \\
\hline $\operatorname{met} E 3 m e t H 4 \times \operatorname{met} A 6$ & $444 / 661$ & $32 \cdot 8$ \\
\hline metE 3 metH5 5 × metA 253 & $395 / 589$ & $32 \cdot 9$ \\
\hline metE3metH9 $\times$ metA1303 & $363 / 543$ & $33 \cdot 2$ \\
\hline metE3metH10 × metA1599 & $478 / 721$ & $33 \cdot 7$ \\
\hline metE 3 met $H 13 \times$ metA1 & $422 / 628$ & $32 \cdot 8$ \\
\hline
\end{tabular}

* Selection was on $\mathrm{MM}$ agar+vitamin $\mathrm{B}_{12}+$ homocysteine and replication was to $\mathrm{MM}$ agar+vitamin $\mathrm{B}_{12}$. Correction was made for met $E^{+}$metH recombinants which are phenotypically wild (see text).

Co-transduction was not detected between methionine and arginine mutants.

\section{Discussion}

The nutritional requirements of the met $A, E$ and $F$ auxotrophs indicate that the methione pathways (fig. 1) of S. typhimurium (Smith and Childs, 1966), E. coli (Balish and Shapiro, 1966), St. aureus (Harmon et al., 1966) and Ps. aeruginosa (Calhoun and Feary, 1969) also function in $P$. mirabilis. $P$. mirabilis methylates homocysteine normally via the met $E$ ( $\mathcal{N}^{5}$-methyltetrahydropteroyltriglutamate-homocysteine transmethylase) route and via met $H$ (cobalamin-dependent $\mathcal{N}^{5}$-methyltetrahydrofolate-homocysteine transmethylase) only when supplied with vitamin $B_{12}$ as described for $E$. coli and S. typhimurium (Childs and Smith, 1969). In Aerobacter aerogenes both routes function without a requirement for vitamin $\mathrm{B}_{12}$ (Morningstar and Kisliuk, 1965) but in Ps. denitrificans (Lago and Demain, 1969) and in mammalian cells (Mangum and North, 1968) only the met $H$ route functions. Fungi and higher plants (Lago and Demain, 1969) and apparently also Ps. aeruginosa (Calhoun and Feary, 1969) synthesise methionine exclusively via the metE route.

The growth response of met $E$ and $F$ auxotrophs to SMC indicates that $P$. mirabilis synthesises methionine via an alternate route also present in Neurospora (Wiebers and Garner, 1964) but absent in E. coli (Grabow and Smit, 1967) and Ps. aeruginosa (Calhoun and Feary, 1969). The phenotypical similarity between met $A$ auxotrophs of $P$. mirabilis and the me-5 mutant of Neurospora is in agreement with methionine synthesis via SMG (fig. 1) in $P$. mirabilis since $m e-5$ has a block in the SMC route (Moore and Thompson, 1967). Methionine synthesis in $P$. mirabilis may be regulated like that in 
$S$. typhimurium since the met $f$ and $K$ mutants of $P$. mirabilis are phenotypically similar to the regulatory mutants of $S$. typhimurium (Lawrence et al., 1968). Overproduction of methione by the met $f$ and $K$ mutants of $P$. mirabilis was possibly not detected because of insensitivity of the syntrophism test used (Lawrence et al., 1968). Although mutants deficient in the utilisation of D-methionine were not isolated, the finding that methionineless $P$. mirabilis auxotrophs grow equally well with both isomers of methionine indicates that the conversion of $\mathrm{D}$ - to L-methionine via keto-methionine operative in $E$. coli (Cooper, 1966) may also occur in P. mirabilis.

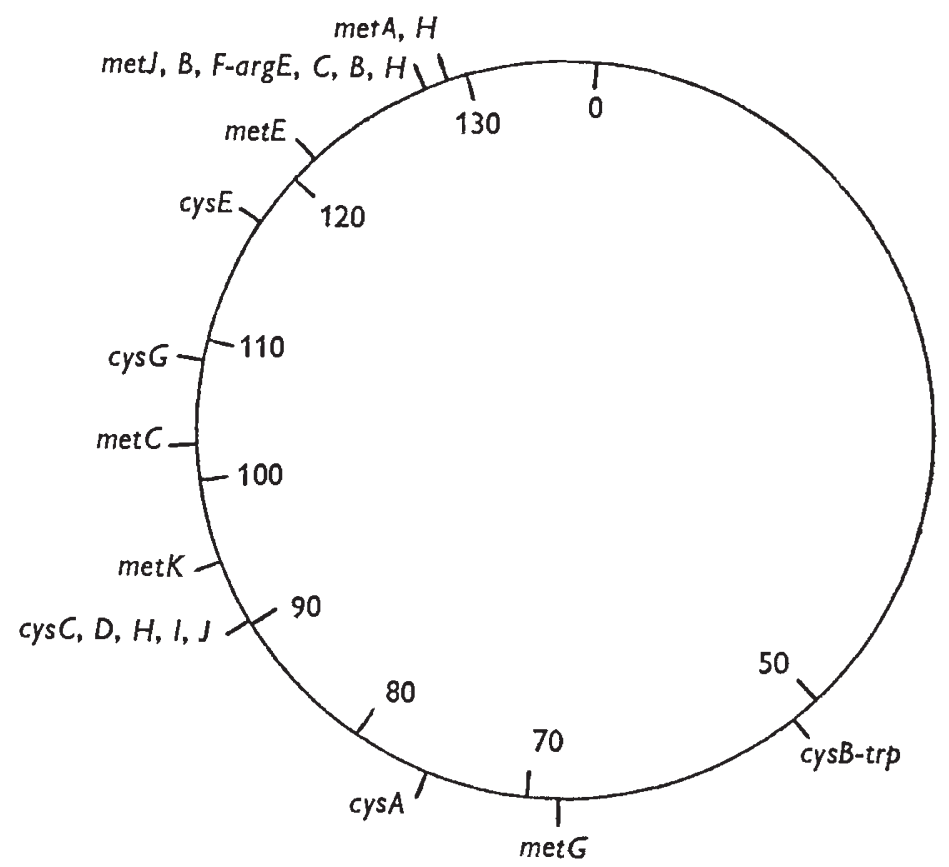

Frg. 2.-Topography of methionine genes in Salmonella typhimurium (after Ayling and Chater, 1968; Sanderson, 1970). Genes are shown on the outside of the circle; arabic numbers on the inside indicate interrupted conjugation time intervals in min. Linked genes appear on the same line in clockwise order from left to right.

Transductional analysis of the methionine mutants showed that their sites of mutation fell into 6 closely-linked clusters possibly representing six genes. The topography of $P$. mirabilis mutants is partly in agreement with that of methionine genes in $S$. typhimurium (fig. 2). Met $A$ and $H$ mutants are linked in both organisms. In $S$. typhimurium the linkage is 35 per cent. (Ayling and Chater, 1968) or 15-22 per cent. (Childs and Smith, 1969) and in P. mirabilis 33 per cent. Non-linkage of metE and $K$ to other met mutants is also a feature of $S$. typhimurium (see Sanderson, 1970). $P$. mirabilis differs from $S$. typhimurium in that its metf and $F$ mutants are not linked to one another or to arginine mutants. Partial agreement of gene topography in $P$. mirabilis, $S$. typhimurium and $E$. coli has also been reported for arginine genes (Prozesky, 1968, 1969). Genetical differences between $P$. mirabilis and $E$. coli or $S$. typhimurium are expected (Marmur, Falkow and Mandel, 1963) since their guanine + cytosine molar contents are $38-41$ per cent., 50 per cent. (Hill, 1966) and 50-52 per cent. (Marmur et al., 1963), respectively. 


\section{Summary}

1. The nutritional requirements of auxotrophs of four possible structural genes indicate that Proteus mirabilis may synthesise methionine via two pathways. One is that of Salmonella typhimurium, Escherichia coli and Pseudomonas aeruginosa while the other involves S-methylcysteine as in Neurospora crasa.

2. Growth requirements of $m e t E$ and $H$ auxotrophs indicate that $P$. mirabilis methylates homocysteine by the two routes of $S$. typhimurium and E. coli.

3. The properties of two groups of mutants resistant to inhibition by methionine analogues suggests that the regulation of methione synthesis in $P$. mirabilis may be similar to that in $S$. typhimurium. Methionine auxotrophs deficient in D-methione utilisation were not encountered.

4. The genetical topography of the $P$. mirabilis mutants corresponds to that of $S$. typhimurium in that met $A$ and $H$ are co-transducible and $m e t E$ and $K$ are not linked to other met mutants. Differences are that met $f$ and $F$ are not co-transducible and they are not linked to the arginine cluster in $P$. mirabilis.

Acknowledgments. - O-succinyl-DL-homoserine was kindly prepared by Dr J. H. Jordaan of the Division of Life Sciences of the South African Atomic Energy Board. This work was partly supported by grants from the South African Medical Research Council to Professor J. N. Coetzee.

\section{REFERENCES}

ADAMS, M. н. 1959. Bacteriophages. Interscience Publishers, New York.

ADELBERG, E. A., MANDEL, M., AND Chein ChING Chen, G. 1965. Optimal conditions for mutagenesis by $\mathcal{N}$-methyl- $\mathcal{N}^{\prime}$-nitro- $\mathcal{N}$-nitrosoguanidine in Escherichia coli K12. Biochem. biophys. Res. Commun., 18, 788-795.

ALBERTS, B. M., AND FREY, L. 1970. T4 bacteriophage gene 32: A structural protein in the replication and recombination of DNA. Nature, Lond., 227, 1313-1318.

AYLING, P. D., AND CHATER, K. F. 1968. The sequence of four structural and two regulatory methionine genes in the Salmonella typhimurium linkage map. Genet. Res., Camb., 12, 341354.

BALISH, E., AND SHAPIRO, s. K. 1966. Cystathionine as a precursor of methionine in Escherichia coli and Aerobacter aerogenes. J. Bact., 92, 1331-1336.

Galmoun, D. H., AND FEARy, T. w. 1969. Transductional analysis of Pseudomonas aeruginosa methionineless auxotrophs. 7. Bact., 97, 210-216.

CAUTHEN, S. E., FOSTER, M. A., AND woods, D. D. 1966. Methionine synthesis by extracts of Salmonella typhimurium. Biochem. 7., 98, 630-635.

CHATER, K. F., AND ROWBURy, R. J. 1970. A genetical study of the feedback-sensitive enzyme of methionine synthesis in Salmonella typhimurium. 7. gen. Microbiol., 63, 111-120.

ChILds, J. D., AND smith, D. A. 1969. New methionine structural gene in Salmonella typhimurium. F. Bact., 100, 377-382.

Coetzee, J. N. 1961. Lysogenic conversion in the genus Proteus. Nature, Lond., 189, 946.

COETZEE, J. N., AND SACKs, T. G. 1960a. Intrastrain transduction in Proteus mirabilis. Nature, Lond., 185, 869-870.

COETZEe, J. N., AND SACKs, T. G. 1960b. Transduction of streptomycin resistance in Proteus mirabilis. F. gen. Microbiol., 23, 445-455.

Coetzee, J. N., AND smir, J. A. 1970. Properties of Proteus mirabilis phage 13 vir. J. gen. Virol., 9, 247-249.

coetzee, J. N., SMTt, J. A., AND PRozesky, o. w. 1966. Properties of Providence and Proteus morganii transducing phages. 7. gen. Microbiol., 44, 167-176.

COOPER, s. 1966. Utilization of D-methionine by Escherichia coli. 7. Bact., 92, 328-332.

DEMEREC, M., AND OZEKI, H. 1959. Tests for allelism among auxotrophs of Salmonella typhimurium. Genetics, 44, 269-278. 
FLAVIN, M., AND SLAUGhTER, C. 1965. Synthesis of the succinic ester of homoserine, a new intermediate in the bacterial biosynthesis of methionine. Biochemistry, Wash., 4, 13701375.

GALIVAN, J., AND HUENNEKENS, F. M. 1970. Resolution of the methionine synthetase system from Escherichia coli K-12. Biochem. biophys. Res. Commun., 38, 46-51.

GLANSDORFF, N. 1965. Topography of cotransducible arginine mutations in Escherichia coli K-12. Genetics, 51, 167-179.

grabow, w. o. K., And smit, J. A. 1967. Methionine synthesis in Proteus mirabilis. F. gen. Microbiol., 46, 47-57.

GROSS, T. S., AND ROWBURY, R. J. 1971. Biochemical and physiological properties of methionyl-sRNA synthetase mutants of Salmonella typhimurium. 7. gen. Microbiol., 65, $5-21$.

HARMON, S. A., BALDWIN, J. N., TIEN, w.-C., AND CRITZ, D. G. 1966. Co-transduction of the genetic determinants of synthesis of penicillinase and methionine in Staphylococcus aureus. Can. F. Microbiol., 12, 973-977.

HARTMAN, P. E., LOPER, J. C., AND ŠERMAN, D. 1960. Fine structure mapping by complete transduction between histidine-requiring Salmonella mutants. 7. gen. Microbiol., 22, 323-353.

HILL, L. R. 1966. An index to deoxyribonucleic acid base compositions of bacterial species. 7. gen. Microbiol., 44, 419-437.

HUANG, н. т. 1963. Accumulation of L-homolanthionine by an Escherichia coli mutant. Biochemistry, Wash., 2, 296-298.

ImikAwA, H., AND DEMEREC, M. 1967. Ditto deletions in the cys $C$ region of the Salmonella chromosome. Genetics, 55, 63-68.

JACOB, F., AND MONOD, J. 1961. On the regulation of gene activity. Cold Spring Harb. Symp. quant. Biol., 26, 193-211.

JoNeS, D., AND SNEATH, P. H. A. 1970. Genetic transfer and bacterial taxonomy. Bact. Rev., $34,40-81$.

LAGO, в. D., AND DEMAIN, A. L. 1969. Alternate requirement for vitamin $B_{12}$ of methionine in mutants of Pseudomonas denitrificans, a vitamin $\mathrm{B}_{12}$-producing bacterium. 7. Bact., 99, 347-349.

LAMPEN, J. O., JONES, M. J., AND PERKINS, A. B. 1947. Studies on the sulfur metabolism of Escherichia coli. I. The growth characteristics and metabolism of a mutant strain requiring methionine. Arch. Biochem., 13, 33-45.

LAWRENCE, D. A., SMITH, D. A., AND ROWBURY, R. J. 1968. Regulation of methionine synthesis in Salmonella typhimurium: Mutants resistant to inhibition by analogues of methionine. Genetics, 58, 473-492.

LEDERBERG, J., AND LEDERBERG, E. M. 1952. Replica plating and indirect selection of bacterial mutants. 7. Bact., 63, 399-406.

MANGUM, J. H., AND NORTH, J. A. 1968. Vitamin $B_{12}$ dependent methionine biosynthesis in HEp-2 cells. Biochem. biophys. Res. Commun., 32, 105-110.

MARMUR, J., FALKOW, S., AND MANDEL, M. 1963. New approaches to bacterial taxonomy. Ann. Rev. Microbiol., 17, 329-372.

MOORE, D. P., AND THOMPSON, J. F. 1967. Methionine biosynthesis from S-methylcysteine by thiomethyl transfer in Neurospora. Biochem. biophys. Res. Commun., 28, 474-479.

MORNINGSTAR, J. F., JUN., AND KISLIUK, R. L. 1965. Interrelations between two pathways of methionine biosynthesis in Aerobacter aerogenes. 7. gen. Microbiol., 39, 43-51.

Prozesky, o. w. 1967. Arginine synthesis in Proteus mirabilis. 7. gen. Microbiol., 49, 325-334. PROZESKY, O. W. 1968. Transductional analysis of arginineless mutants in Proteus mirabilis. 7. gen. Microbiol., 54, 127-143.

Prozesky, o. w. 1969. Regulation of the arginine patloway in Proteus mirabilis. 7. gen. Microbiol., 55, 89-102.

ProzesKy, O. W., AND COEtZeE, J. N. 1966. Linked transduction in Proteus mirabilis. Nature, Lond., 209, 1262.

PROzesKy, O. W., DE KLeRk, H. C., AND COETZeE, J. N. 1965. The morphology of Proteus bacteriophages. 7. gen. Microbiol., 41, 29-36.

SANDERSON, K. E. 1970. Current linkage map of Salmonella typhimurium. Bact. Rev., 34, 176-193.

sмгтн, D. A. 1961. Some aspects of the genetics of methionineless mutants of Salmonella typhimurium. F. gen. Microbiol., 24, 335-353.

SMITH, D. A., AND CHILDS, J. D. 1966. Methionine genes and enzymes of Salmonella typhimurium. Heredity, 21, 265-286. 
TAYLOR, A. L. 1970. Current linkage map of Escherichia coli. Bact. Rev., 34, 155-175.

WIEBERS, J. L., AND GARNER, H. R. 1964. Use of S-methylcysteine and cystathionine by methionineless Neurospora mutants. F. Bact., 88, 1798-1804.

WOODS, D. D., FOSTER, M. A., AND GUEST, J. R. 1965. Cobalamin-dependent and independent methyl transfer in methionine biosynthesis in Transmethylation and Methionine Biosynthesis (ed. S. K. Shapiro and F. Schlenk). University of Chicago Press, Chicago, 138-154. 